\title{
Martensitic Transformation in CuAlMn and CuAlNi Melt Spun Ribbons
}

\author{
J. Dutkiewicz, J. Morgiel, T. Czeppe and E. Cesari* \\ Institute of Metallurgy and Materials Science of the Polish Academy of Sciences, ul. Reymonta 25, \\ 30-059 Kraków, Poland \\ * Physics Department, University of Balearic Islands, Cra.de Valldemossa km7.5, \\ 07071 Palma de Mallorca, Spain
}

\begin{abstract}
The martensitic transformation was studied in CuAlMn and CuAlNi alloys transforming at elevated temperatures i.e. $70-250^{\circ} \mathrm{C}$. All alloys possessed mixed $18 \mathrm{R}$ and $2 \mathrm{H}$ structure of martensite. Splat quenching caused a direct formation of martensite and a considerable decrease of the grain size from about $100 \mu \mathrm{m}$ in the bulk (in spite of TiB additions) down to about $2 \mu \mathrm{m}$. The martensite was less prone to stabilization as in bulk water quenched alloys. The $\mathrm{DO}_{3}$ domains size was not altered in ribbons due to insufficient cooling in the solid state after casting. Their size was considerably lowered in ribbons cooled directly in water after casting. Martensitic transformation temperatures were shifted to lower temperatures by $20-50^{\circ} \mathrm{C}$, but the transformation hysteresis was $10-20^{\circ} \mathrm{C}$ broader in all alloys investigated. Transmission electron microscope (TEM) in-situ heating/cooling experiments allowed one to follow the nucleation of martensite in splat quenched ribbons due to their fine grain size. It appeared that martensite needles nucleated at the grain boundaries. Growing needles, approaching grain boundaries induce formation of other plates at adjacent grains.
\end{abstract}

\section{INTRODUCTION}

Copper base alloys subjected to splat quenching possess the metastable $\beta$ or martensitic structure [1-6]. The grain size is considerably lower (in the range of a few $\mu \mathrm{m}$ ), what causes improvement of mechanical properties when compared to cast bulk alloys [2-5]. There exist a number of works on rapidly quenched $\mathrm{CuAlNi}$ [1-5] and CuAlZn [6] alloys, but no information was found on the effect of rapid quenching on the martensitic transformation in CuAIMn alloys. The drop of transformation temperatures in rapidly quenched ribbons is attributed to a significant decrease of grain size [4] or to the decreased degree of ordering [2,7]. It seems however that the effect of grain size is very important in this case, since in bulk alloys it was well established that $M_{s}$ temperature drops proportionally to (grain size) ${ }^{-1 / 2}[8,9]$. A small drop of $M_{s}$ was explained by Scarsbrook et al [7] by zinc loss during ribbon fabrication. No difference in ordered domain size in bulk alloys and in the ribbons stated in $[3,4]$ suggests that the degree of order varies depending on the ribbon preparation method. It is probably not the only reason for the drop of transformation temperatures in ribbons. The other problem which is not clear is the stabilization of martensite in ribbons. Scarsbrook et al [7] suggested that the equilibrium stabilization in CuAlZn ribbons occurs more rapidly than in a large grain size material and consequently excellent SME properties of the ribbon can be maintained only over a few weeks at room temperature. This effect however was not reported in CuAINi or CuAlMn alloys and it is therefore the subject of the present study. A small grain material was used also to study in-situ nucleation of martensite, since it is difficult to follow in usually large grain bulk alloys.

\section{EXPERIMENTAL PROCEDURE}

The investigated alloys were cast in Balzers vacuum induction furnace under protective argon atmosphere. The alloy compositions are listed in the Table 1. All Cu-Al-Mn alloys contained a small addition of Ti5B as a grain refiner, leading to a final grain size not exceeding $100 \mu \mathrm{m}$. After casting, the alloys were hot rolled and then cut and quenched from $850^{\circ} \mathrm{C}$ to water or to a melted salt bath at different temperatures. 
Martensitic transformation temperatures were measured using a $\mathrm{Du}$ Pont 910 calorimeter at a cooling/heating rate of $20 \mathrm{~K} / \mathrm{min}$. Melt spun ribbons were cast on the rotating copper wheel at the linear speed of $26 \mathrm{~m} / \mathrm{sec}$, ejecting liquid alloy from a quartz crucible through a hole of $0.7 \mathrm{~mm}$ diameter, using gas pressure of $0.12 \mathrm{MPa}$. Casting was performed within a box with helium atmosphere. Ribbons obtained were 30-50 $\mu \mathrm{m}$ thick and $2-3 \mathrm{~mm}$ broad. The structure was investigated using Philips CM20 transmission

Table 1.Chemical composition of alloys investigated

\begin{tabular}{|c|c|c|c|c|c|}
\hline Alloy & $1 \mathrm{M}(17)$ & $2 \mathrm{M}(18)$ & $3 \mathrm{M}(10 \mathrm{a})$ & $1 \mathrm{~N}(81)$ & $2 \mathrm{~N}(83)$ \\
\hline $\mathrm{Cu}(\mathrm{wt} \%)$ & 84.5 & 84.1 & 86.6 & 85 & 83.3 \\
\hline $\mathrm{Al}(\mathrm{wt} \%)$ & 11.5 & 10.4 & 10.4 & 11 & 12.5 \\
\hline $\mathrm{Mn}(\mathrm{wt} \%)$ & 4 & 4.1 & 3 & - & - \\
\hline $\mathrm{Ni}(\mathrm{wt} \%)$ & - & - & - & 4 & 4 \\
\hline $\mathrm{Ti}_{5} \mathrm{~B}(\mathrm{wt} \%)$ & 0.1 & 0.1 & 0.1 & - & - \\
\hline
\end{tabular}

electron microscope equipped with Oxford Instruments nondispersive energy spectrometer. In-situ studies were performed using Philips EM301 transmission electron microscope with original heating stage. Thin foils were obtained at subzero temperature using jet electropolishing in $33 \% \mathrm{HNO}_{3}$ and $67 \% \mathrm{CH}_{3} \mathrm{OH}$ electrolyte at voltage of $9 \mathrm{~V}$.

\section{RESULTS AND DISCUSSION}

\subsection{Calorimetric measurements}

Table 2 presents the results of calorimetric measurements. One can see that the start temperatures of the austenite/martensite transformation and of the reverse one, $M_{s}$ and $A_{s}$ respectively, are generally different in the hot-rolled and quenched massive material, and in the melt spun ribbons. This difference depends strongly on the microstructure of the sample, especially on the grain size and defects concerntration. In the case of ribbons with drastically smaller grain size (typically 50 times) than in the massive samples, when the martensite stabilization during the quenching of the massive sample was carefully avoided, the $M_{s}$ and As of the ribbons were generally lower, giving $\Delta \mathrm{M}_{\mathrm{s}}$ of about 8 to $51 \mathrm{deg}$. Differences in $\mathrm{A}_{\mathrm{s}}$ temperatures were slightly different. In alloys with high $\mathrm{M}_{s}$ temperatures, $1 \mathrm{M}$ and $2 \mathrm{~N}$, this difference is difficult to

Table 2. Results of calorimetric measurements of investigated alloys. $R$ denotes melt spun ribbons. Temperatures Ms and As, and temperatures differences in ${ }^{\circ} \mathrm{C}$, heat of transformations $\mathrm{Q}$ in $\mathrm{J} / \mathrm{g} ; \Delta \mathrm{M}_{\mathrm{s}}=\mathrm{M}_{\mathrm{s}}$ (bulk) $-\mathrm{M}_{\mathrm{s}}$ (ribbon); $\Delta \mathrm{A}_{\mathrm{s}}=$ $A_{\text {, }}$ (bulk)-A,(ribbon)

\begin{tabular}{|l|c|c|c|c|c|c|c|c|c|c|}
\hline Alloy & \multicolumn{7}{|c|}{$\mathrm{Cu}-\mathrm{Al}-\mathrm{Mn}$} & \multicolumn{4}{c|}{$\mathrm{Cu}-\mathrm{Al}-\mathrm{Ni}$} \\
\hline & $2 \mathrm{M}$ & $2 \mathrm{M}_{\mathrm{R}}$ & $3 \mathrm{M}$ & $3 \mathrm{M}_{\mathrm{R}}$ & $1 \mathrm{M}$ & $1 \mathrm{M}_{\mathrm{R}}$ & $1 \mathrm{~N}$ & $1 \mathrm{~N}_{\mathrm{R}}$ & $2 \mathrm{~N}$ & $2 \mathrm{~N}_{\mathrm{R}}$ \\
\hline $\mathrm{M}_{\mathrm{s}}$ & 95 & 79 & 114 & 92 & 162 & 154 & 127 & 76 & 232 & 205 \\
\hline$\Delta \mathrm{M}_{\mathrm{s}}$ & 16 & --- & 22 & --- & 8 & --- & 51 & -- & 27 & -- \\
\hline $\mathrm{A}_{\mathrm{s}}$ & 118 & 107 & 112 & 111 & 178 & 165 & 130 & 78 & 247 & 210 \\
\hline$\Delta \mathrm{A}_{\mathrm{s}}$ & 11 &.-- & 1 & --- & 13 & --- & 52 & -- & 37 & -- \\
\hline $\mathrm{A}_{\mathrm{r}-\mathrm{M}_{\mathrm{r}}}$ & 69 & 95 & 62 & 70 & 58 & 74 & 35 & 61 & 44 & 57 \\
\hline $\mathrm{Q}_{\mathrm{A}-\mathrm{M}}$ & 8.1 & 8,0 & 6,0 & 7,5 & 6,3 & 9,1 & 9,6 & 6,2 & 10,2 & 13,2 \\
\hline $\mathrm{Q}_{\mathrm{M}-\mathrm{A}}$ & 11.1 & 8,2 & 6,5 & 7,0 & 5,0 & 9,1 & 10,6 & 7,7 & 13,2 & 5,4 \\
\hline
\end{tabular}


explain, but may be related to the changes in defect interactions at higher temperature range. One can not exclude a small stabilisation effect of the in the ribbons of $\mathrm{Cu}-\mathrm{Al}-\mathrm{Mn}$ alloys. The another typical effect is a much broader transformation temperature range (measured as $A_{f}-M_{f}$ ) in the case of the ribbons, typically 1.3 times. Calorimetric experiments confirmed high sensitivity of the microstructure of rapidly solidified ribbons both on the casting conditions, especially cooling effectiveness and the thermal history of the sample. Additional cooling applied during casting procedure lead to a drop of temperature range of the observed thermal effects. About 1 month ageing at the room temperature lead to the opposite effect in transformation temperatures. This observations support the opinion that only if the casting conditions and the thermal history of the sample were carefully controlled.
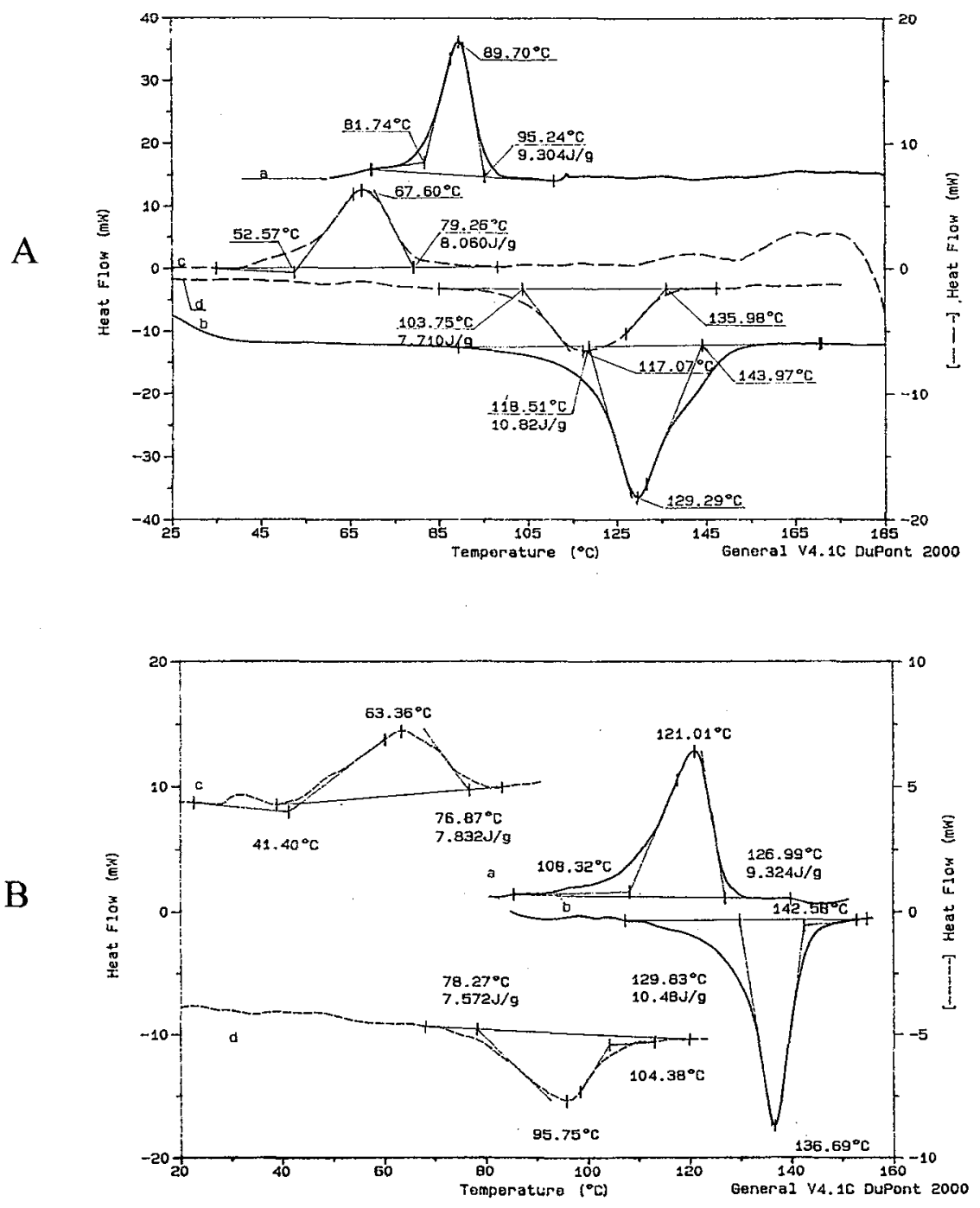

Fig. 1. Calorimetric curves for massive and ribbon samples. A: alloy $3 \mathrm{M}: \mathrm{B}$ : alloy $2 \mathrm{~N}$ Curves: a, b massive samples; c, d ribbons; curves a and $\mathrm{c}$-martensitic transformation during cooling, $\mathrm{b}$ and $\mathrm{d}$ - reverse transformation during heating. Heating and cooling rate $20 \mathrm{~K} / \mathrm{min}$. 


\subsection{TEM studies}

Fig. 2 shows a TEM micrograph taken from the melt spun ribbon of alloy $1 \mathrm{MR}$. At a relatively small magnification one can see that the grain size vary between 2 and $5 \mu \mathrm{m}$. It causes a small plate size of thickness in the range $0.1-0.3 \mu \mathrm{m}$. They are characterised by mostly parallel arrangement and a limited number of orientation variants as proved by electron diffraction studies. The $18 \mathrm{R}$ and $2 \mathrm{H}$ martensite structures were identified. It is in accord with earlier studies of the structure of bulk CuAlMn martensite [10] where the same martensite structures were identified.
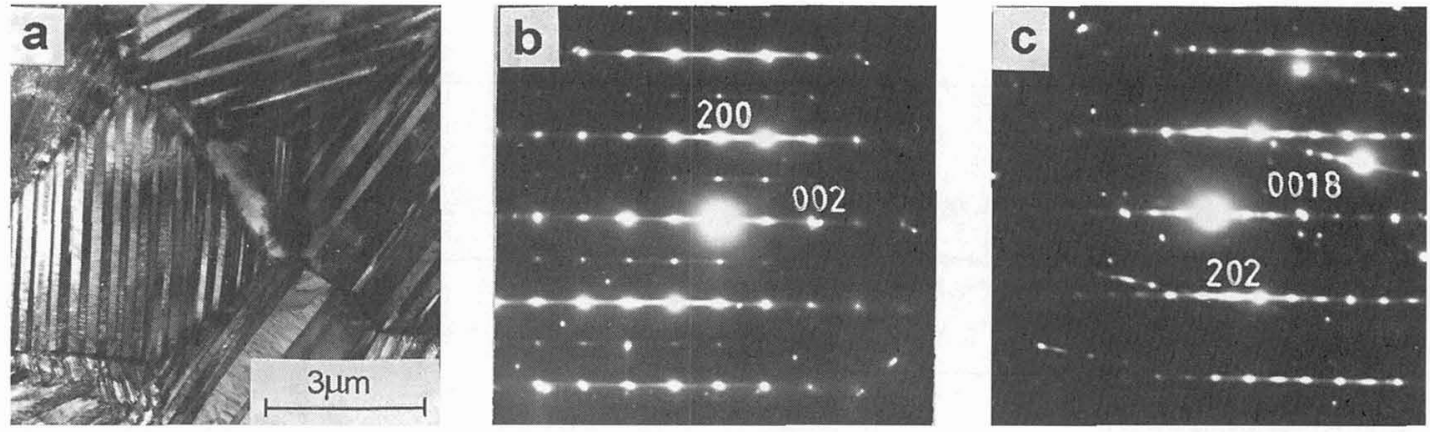

Fig. 2. Transmission electron micrograph taken from alloy IMR and corresponding selected area diffraction pattern (SADP) showing $2 \mathrm{H}(\mathrm{b})$ and $18 \mathrm{R}(\mathrm{c})$ structures.
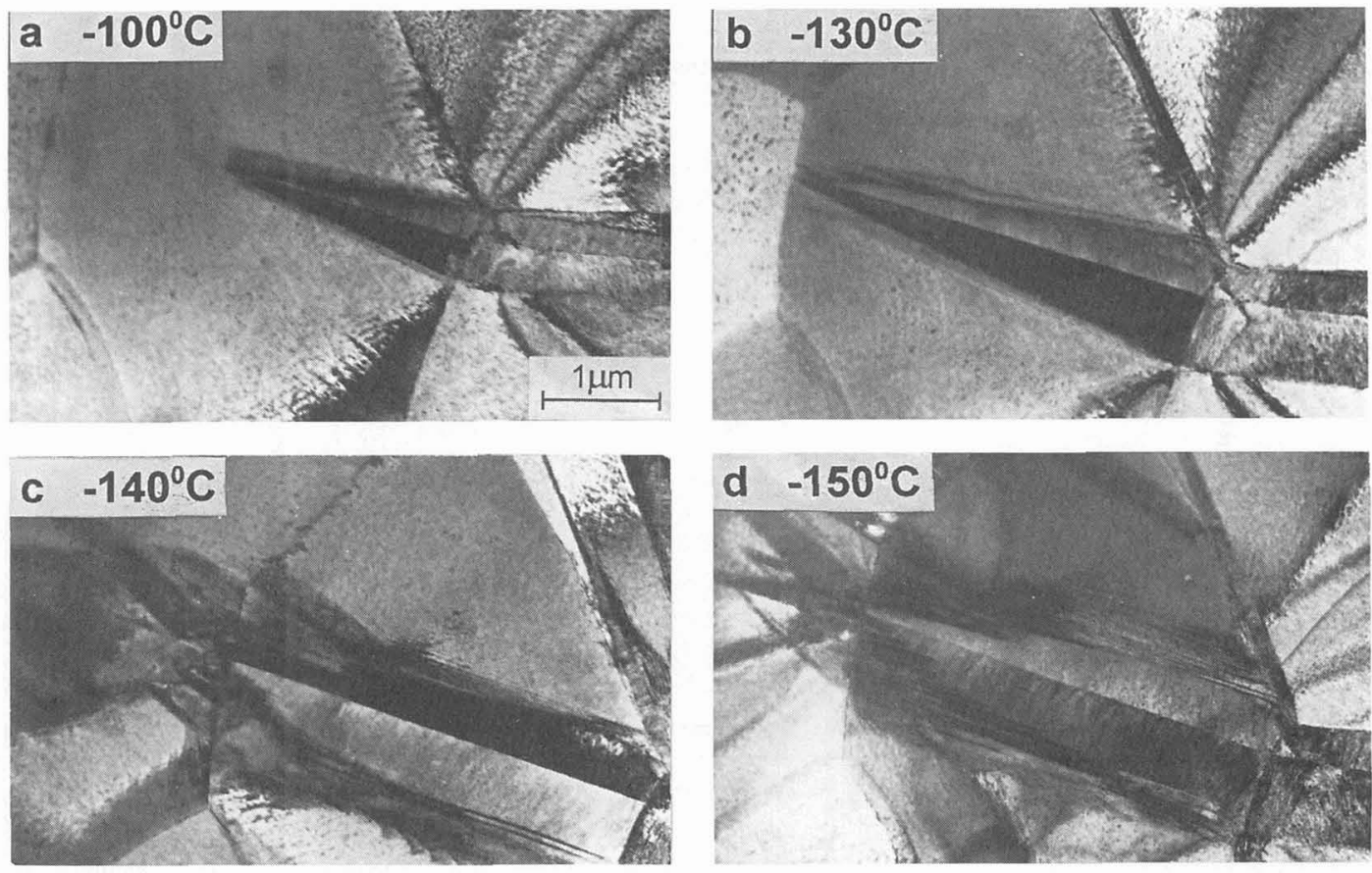

Fig. 3. In-situ cooling of a sample from melt spun ribbon of alloy $3 \mathrm{MR}$ heated to $\beta$ range and then cooled to $-100{ }^{\circ} \mathrm{C}$ (a), $-130^{\circ} \mathrm{C}(\mathrm{b}),-140^{\circ} \mathrm{C}(\mathrm{c}),-150^{\circ} \mathrm{C}(\mathrm{d})$, 
Fig. 3 shows a series of TEM micrographs made during in-situ cooling of alloy $2 \mathrm{M}$ previously heated to $\beta$ range. The martensite did not appear on cooling at temperatures close to $M_{s}$, but during undercooling of $-170^{\circ} \mathrm{C}$ what is caused by different nucleation conditions in thin foil, than the massive sample, most probably due to a stress relaxation in thin areas. This effect was not observed in NiTi in-situ cooling experiments of Saburi and Nenno [11], but the temperature was not controlled there. Nevertheless, the nucleation of plates is very similar as reported there i.e the propagation of martensite across grain boundaries and nucleation of a new plates at grain boundaries, in places where the growing needle approaches grain boundary. This is caused by exertion of stress in the adjacent grain, which induces a new martensite plate.

In in-situ heated samples from melt spun ribbons a subgrain structure appears within the grains of the $\beta$ phase (Fig.4). It is most probably caused by a high concentration of defects in melt spun ribbon which accumulates at the plate boundaries. During the reverse transformation those defects are inherited within the $\beta$ phase causing formation of the subgrain structure. However, no correlation between this structure and nucleation of martensite was observed.

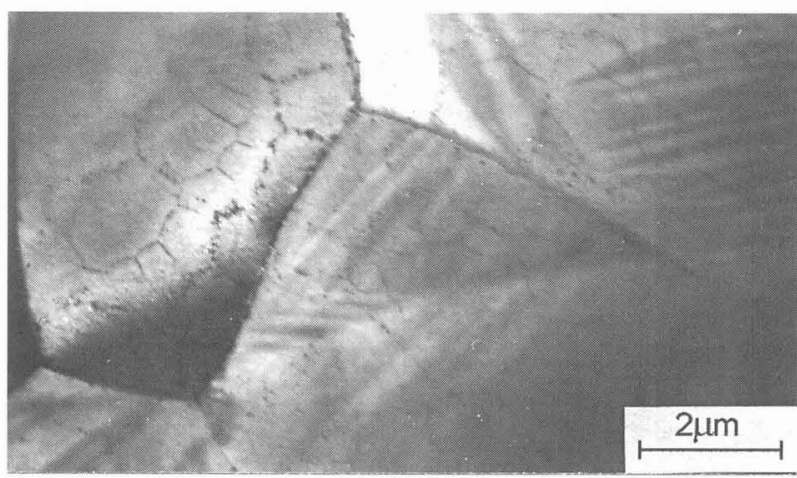

Fig. 4. TEM micrograph of in-situ heated sample from the melt spun ribbon of alloy $3 \mathrm{MR}$ in the $\beta$ phase

Another difference between the bulk and the ribbon was the ordered domain size. Contrary to earlier statements [2] larger $\mathrm{DO}_{3}$ domains and similar intensity of superlattice reflections indicate that the degree of order is not smaller in ribbons (Fig.5). This unexpected effect is most probably caused by insufficient cooling of the ribbon leaving the wheel. The ribbon cooled directly in water after casting exhibited smaller domain size, of the order of that in the bulk, similarly like reported in [4].
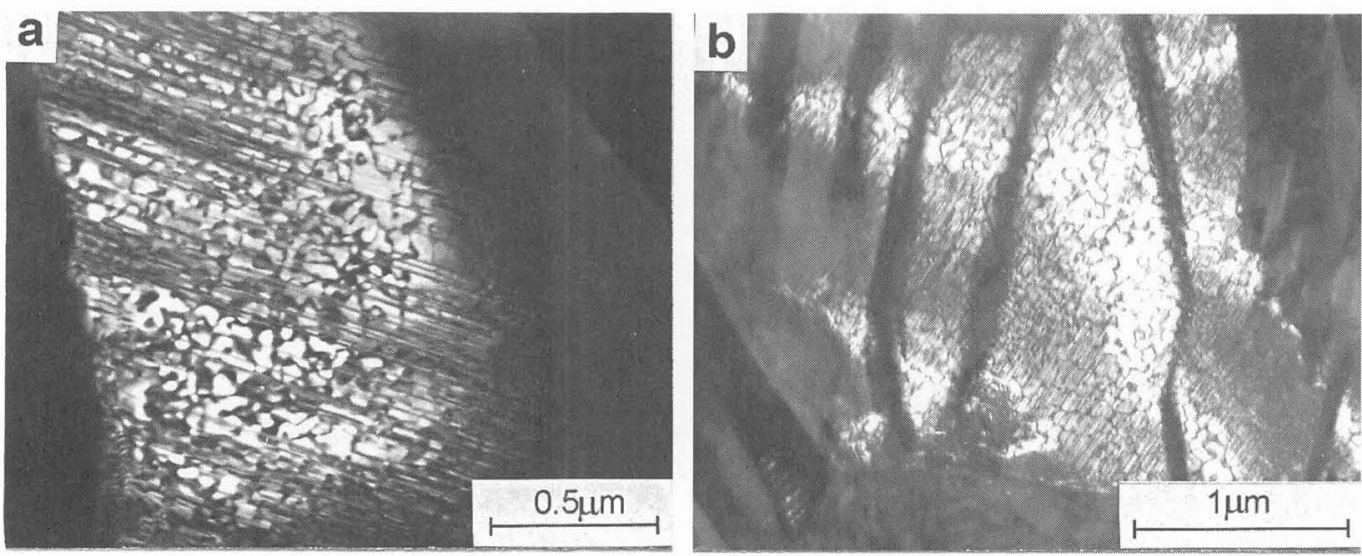

Fig. 5. $\mathrm{DO}_{3}$ domains visible in 111 superlattice reflection in the (a) bulk sainple $1 \mathrm{~N}$, (b) melt spun ribbon of alloy $1 \mathrm{MR}$ 


\section{CONCLUSIONS}

1. The martensitic transformation temperature range of the melt spun ribbons is shifted to lower temperatures when compared to bulk CuAlMn and CuAlNi alloys. It is most probably caused by much smaller grain size in ribbons showing similar order as the bulk material.

2. Ribbons show broader transformation hysteresis than bulk alloys what results from a higher density of defects (subgrains).

3. Small grain size in ribbons enabled observation of the nucleation of martensite at the grain boundaries and propagation of needles across the grains during in-situ cooling experiments.

\section{Acknowledgements}

The partial financial support of the INCO-COPERNICUS Project No IC15-CT96-0704 is gratefully acknowledged.

\section{References}

[1] Wood J.V. J. de Physique Colloque C4 43 (1982) 755-760

[2] Eucken S. Hornbogen E. Martensitic Transformations 86, ed. The Japan Institute of Metals, Sendai 1987 p. $780-785$

[3] Ahmed M., Husain S.W., Iqbal Z., Hashmi F.H and Khan A.Q., Scripta Met., 22 (1988) 803-808

[4] Wood J.V. and Shingu P.H. Met. Trans. A 15A (1984) 471-480

[5] Leu S.S., Chen Y.C. Jean R.D. J. Materials Sci. 27 (1992) 2792-2798

[6] Zhu J.H. Dunne P., Delamore G.W. and Kennon N.F., Martensitic Transformations 92, Monterey Institute for Advanced Studies, Monterey CA 1993 p.1083-1088

[7] Scarsbrook G. and Stobbs W.M., Acta metall. 35 (1987) 47-56

[8] Adnyana D.N., Martensitic transformations 86, The Japan Institute of Metals, Sendai, 1987, p.774-779

[9] Sure G.N. and Brown L.C. Met. Trans. 15A (1984) 1613-1620

[10] Dutkiewicz J., Cesari E., Segui C. and Pons J., J. de Physique IV, Colloque C4 (1991) 229-234

[11] Saburi T. and Nenno S. Martensitic Transformations 86, ed. The Japan Institute of Metals, Sendai 1987 p.671-678 